Check for updates

Cite this: RSC Adv., 2017, 7, 34411

Received 22nd May 2017

Accepted 25th June 2017

DOI: $10.1039 / \mathrm{c} 7 \mathrm{ra05750d}$

rsc.li/rsc-advances

\title{
A water-soluble pillar[5]arene-based chemosensor for highly selective and sensitive fluorescence detection of L-methionine $\uparrow$
}

\begin{abstract}
Qi Lin, (D) *a Lu Liu, ${ }^{a}$ Feng Zheng, ${ }^{a}$ Peng-Peng Mao, ${ }^{a}$ Juan Liu, ${ }^{* b}$ You-Ming Zhang, (D ${ }^{a}$ Hong Yao and Tai-Bao Wei ${ }^{a}$ *a

L-Methionine (L-Met) is an essential amino acid for the human body. The detection of L-Met in water solution is very important. Herein, we report an efficient approach for the fluorescent detection of L-Met with high selectivity and sensitivity in water using a cationic pillar[5]arene-based chemosensor (AWP5). When various L-amino acids are added to the AWP5 water solution, only L-Met can induce fluorescence in AWP5 at $\lambda_{\mathrm{em}}=520 \mathrm{~nm}$, showing dramatic enhancement; thus, other amino acid do not interfere in the L-Met recognition process. AWP5 also shows high sensitivity for L-Met in water, with the lowest detection limit of AWP5 for L-Met being $5.46 \times 10^{-7} \mathrm{~mol} \mathrm{~L}^{-1}$.
\end{abstract}

\section{Introduction}

L-Amino acids play a significant role in chemistry and biology. In particular, L-Met is one of the most essential amino acid for protein synthesis in the human body, which can promote the growth of hair and nails, enhance muscle activity etc. L-Methionine acts as a methyl group donor in many methyltransferase reactions including biosynthesis of phospholipids ${ }^{\mathbf{1}}$ and bioelectrical activity. ${ }^{2}$ Loss of L-methionine in brain cells of aged animals is linked with the loss of dopaminergic $\beta$-adrenergic binding sites and changes in cell membrane composition. ${ }^{3}$ Therefore, the selective detection of L-Met is very important. To date, there are various useful strategies or methods such as artificial chemosensors, high-performance liquid chromatography, and capillary zone electrophoresis ${ }^{4-8}$ that have been applied for the detection of L-amino acids. However, these methods suffer from a number of problems. First, the instrument detection methods often employ expensive equipment. Second, owing to the low water solubility of organic groups, most synthesized chemosensors do not work well in water solution. However, most biological or environmental procedures are carried out in water systems. Therefore, it is still a big challenge and an important task to develop a water soluble chemosensor for the detection L-Met in water.

${ }^{a}$ Key Laboratory of Eco-Environment-Related Polymer Materials, Ministry of Education of China, Key Laboratory of Polymer Materials of Gansu Province, College of Chemistry and Chemical Engineering, Northwest Normal University, Lanzhou, Gansu, 730070, P. R. China. E-mail: linqi2004@126.com; weitaibao@126.com

${ }^{b}$ College of Chemical Engineering, Northwest University for Nationalities, Lanzhou, 730000, P. R. China. E-mail: liujuan656@126.com

$\dagger$ Electronic supplementary information (ESI) available: Experimental details, synthesis of AWP5, NMR spectra, and other materials. See DOI: $10.1039 / \mathrm{c} 7 \mathrm{ra} 05750 \mathrm{~d}$
Recently, pillararene chemistry has undergone rapid development ${ }^{9-16}$ and pillararene derivatives have been widely used in the field of molecular recognition, ${ }^{17-23}$ drug delivery, ${ }^{24-30}$ molecular devices, ${ }^{31-37}$ and so on. Note that two kinds of important watersoluble pillararene derivatives have been developed to date: (1) cationic pillararene ${ }^{38}$ and (2) anionic pillararene. ${ }^{39,40}$ Due to their nice water solubility, inclusion and host-guest properties, these kinds of pillararene derivatives provide a great opportunity for the design of water-soluble chemosensors.

In view of this and based on our research interest in molecule recognition, ${ }^{\mathbf{4 1 - 4 8}}$ herein, we report a novel and efficient way for the detection of L-Met in water via a cationic pillar[5]arenebased chemosensor (AWP5). As shown in Scheme 1, the

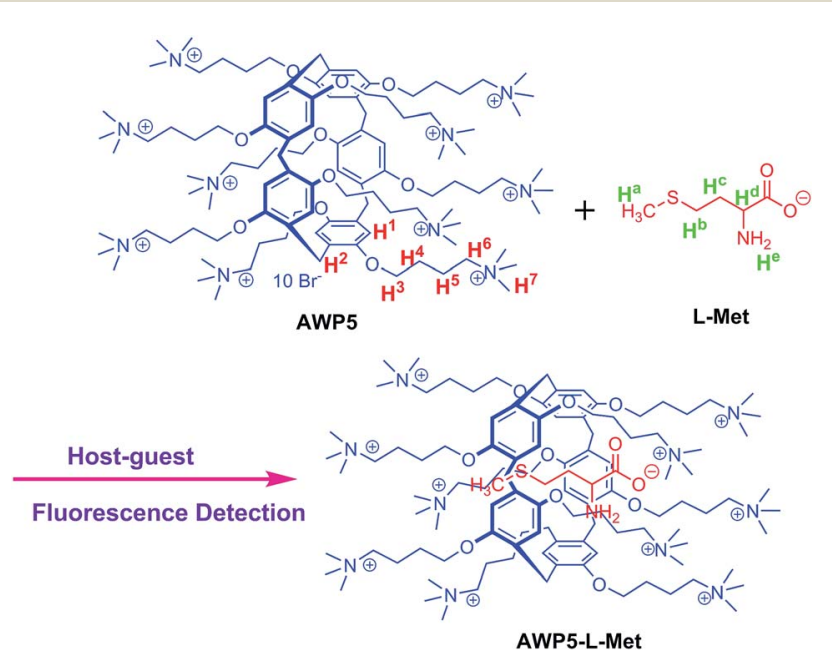

Scheme 1 The chemical structure of AWP5 and possible selective detection mechanism of the sensor AWP5 for L-Met. 
chemosensor AWP5 possesses high water solubility and can enable fluorescence detection of L-Met in water with high selectivity and sensitivity through a host-guest mechanism.

\section{Results and discussion}

Cationic pillar[5]arene (AWP5) was synthesized according to Scheme $\mathbf{S 1 . \dagger}$ To investigate $\mathrm{L}$-amino acid recognition abilities of the sensor AWP5 in water, we carried out a series of host-guest recognition experiments. The recognition profiles of the sensor AWP5 for various L-amino acids, including L- $\alpha$-Ala, L-Arg, L-Cys, L-Gly, L-Lys, L-Pro, L-Met, L-Thr, L-Ser, L-His, L-Val, L-Tyr, L-Asn, LGlu, L-Trp, L-Gln, L-Ile, L-Phe, L-Asp, and L-Leu, were primarily investigated using fluorescence spectroscopy in water.

As shown in Fig. 1, when 10 equiv. of L-Met was added to the water solution of sensor AWP5, a blue fluorescence emission appeared. Moreover, in the corresponding fluorescence spectrum, the maximum emission peak appeared at $617 \mathrm{~nm}$. However, other L-amino acids such as L- $\alpha$-Ala, L-Arg, L-Cys, L-Gly, L-Lys, L-Pro, L-Thr, L-Ser, L-His, L-Val, L-Tyr, L-Asn, L-Glu, L-Trp, LGln, L-Ile, L-Phe, L-Asp, and L-Leu did not induce similar fluorescence changes (Fig. 2 and $\mathrm{S} 10 \dagger$ ). Therefore, in water solution, AWP5 showed specific fluorescence selectivity for L-Met.

To further investigate the efficiency of the sensor AWP5 for LMet detection, we carried out fluorescence titration experiments. As shown in Fig. 3, in the fluorescence spectrum, with an increasing amount of $\mathrm{L}$-Met, emission peak at $594 \mathrm{~nm}$ gradually increased. Furthermore, the detection limit of the fluorescent spectrum changes calculated on the basis of $3 \mathrm{~s} / \mathrm{m}$ (ref. 49 ) is 5.46 $\times 10^{-7} \mathrm{M}$ for L-Met (Fig. S11, ESI $\dagger$ ). Moreover, we carried out similar experiments in the presence of 10 equiv. of L-his (Fig. S12, $\mathrm{ESI} \dagger$ ). The L-Met detection limit was $2.07 \times 10^{-6} \mathrm{M}$ in the presence of 10 equiv. of L-His, which indicated that AWP5 showed high sensitivity for L-Met in the presence of other amino acids.

To further exploit the utility of AWP5 as a selective sensor for L-Met, competitive experiments were carried out in the presence of 10.0 equiv. of L-Met and 2.0 equiv. of various L-amino acids in water. The fluorescence emission spectrum of the sensor AWP5

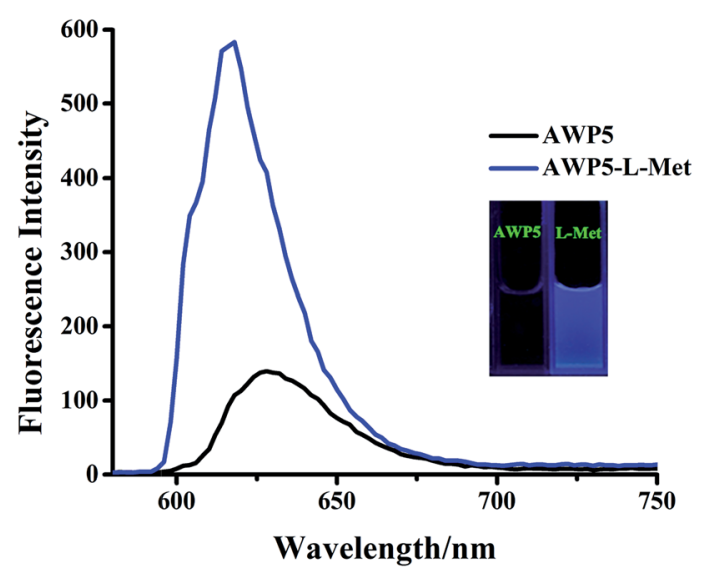

Fig. 1 Fluorescence spectra of AWP5 ( $C=2 \times 10^{-5} \mathrm{~mol} \mathrm{~L}^{-1}$ in water) and the AWP5 water solution after the addition of 10 equiv. of L-Met $\left(\lambda_{\mathrm{ex}}=520 \mathrm{~nm}\right)$.

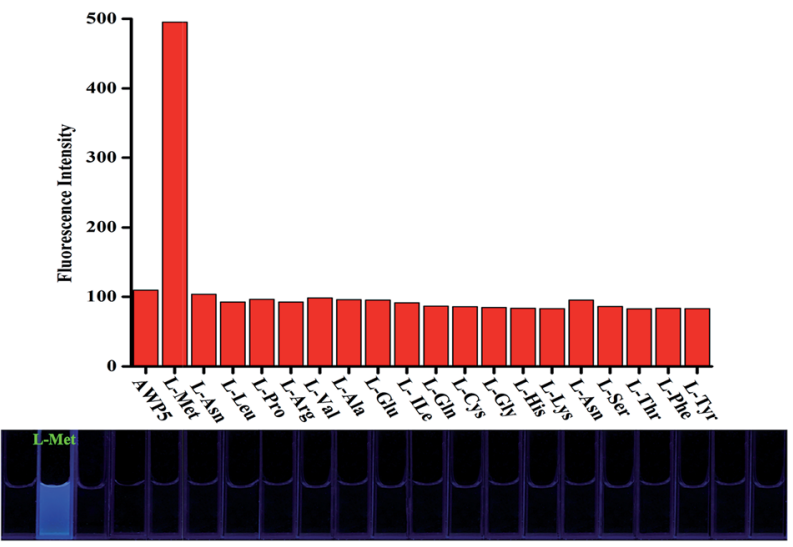

Fig. 2 Fluorescence spectra of the sensor AWP5 in water solution $(2 \times$ $10^{-5} \mathrm{~mol} \mathrm{~L}^{-1}$ ) upon the addition of 10 equiv. of L-Ala, L-Arg, L-Asp, LCys, L-Gln, L-Glu, L-His, L-Ile, L-Gly, L-Asn, L-Leu, L-Lys, L-Met, L-Phe, LPro, L-Ser, L-Thr, L-Trp, L-Tyr, and L-Val $\left(\lambda_{\text {ex }}=520 \mathrm{~nm}\right)$.

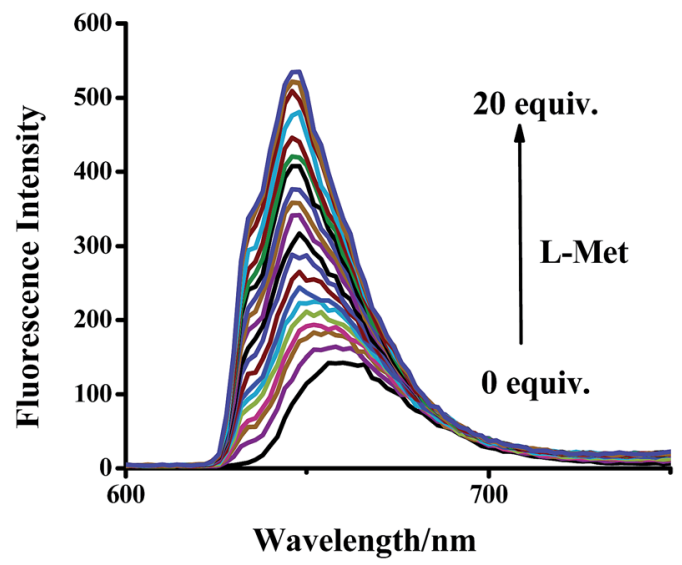

Fig. 3 Fluorescence intensity changes of AWP5 water solution $(C=1$ $\left.\times 10^{-5} \mathrm{~mol} \mathrm{~L}^{-1}\right)$ upon the addition of different amounts of $\mathrm{L}-$ Met $\left(\lambda_{\mathrm{ex}}=\right.$ $520 \mathrm{~nm})$.

with L-Met was not influenced by the subsequent addition of other competing L-amino acids, which indicated that AWP5 had specific selectivity for L-Met (Fig. 4).

The recognition mechanism of AWP5 towards L-Met was investigated by ${ }^{1} \mathrm{H}$-NMR titrations, 2D NOESY-NMR, ESI-mass spectrometry, and job plots. As shown in Fig. 5, in ${ }^{1} \mathrm{H}-\mathrm{NMR}$, upon the addition of L-Met to an AWP5 $\mathrm{D}_{2} \mathrm{O}$ solution, proton peaks of AWP5 and L-Met show obvious shifts. The triplet peaks of $\mathrm{H}_{\mathrm{a}}, \mathrm{H}_{\mathrm{b}}, \mathrm{H}_{\mathrm{c}}$, and $\mathrm{H}_{\mathrm{d}}$ of $\mathrm{L}$-Met show obvious upfield shifts $(\Delta \delta=$ $-0.15,-0.23,-1.54,-0.10,-0.12 \mathrm{ppm})$, which indicates that $\mathrm{L}^{-}$ Met is located in the cavity of AWP5. Simultaneously, the proton peaks of $\mathrm{H}^{1}$ and $\mathrm{H}^{2}$ of AWP5 shift upfield $(\Delta \delta=-0.25$ and -0.40 ppm), which indicate electrostatic interactions between the carboxylic acid groups of L-Met and ammonium salts of AWP5. The electrostatic interactions directly lead to charge transfer from the carboxylate groups of L-Met to the AWP5 ammonium salt groups. By this way, these proton chemical shift changes indicated that the complexation took place between AWP5 and $\mathrm{L}-\mathrm{Met}$ in solution. 


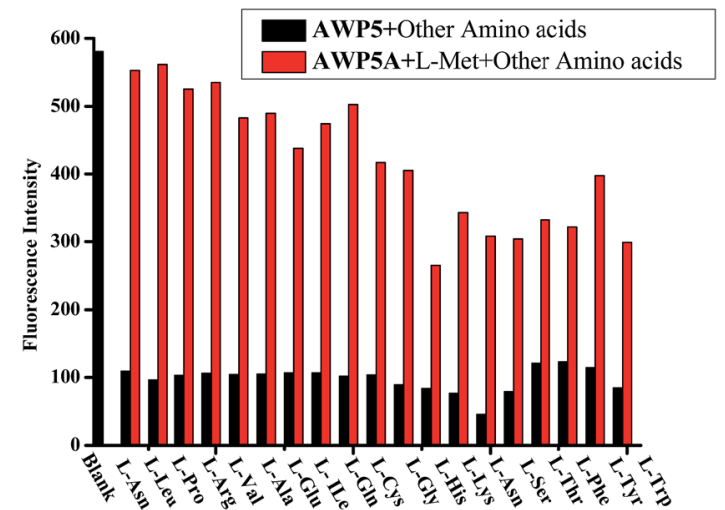

Fig. 4 Fluorescence intensity changes of the sensor AWP5 water solution $\left(1 \times 10^{-5} \mathrm{~mol} \mathrm{~L}^{-1}\right)$ ensemble in the presence of other amino acids ( 2.0 equiv.) $\left(\lambda_{\mathrm{ex}}=520 \mathrm{~nm}\right.$ )

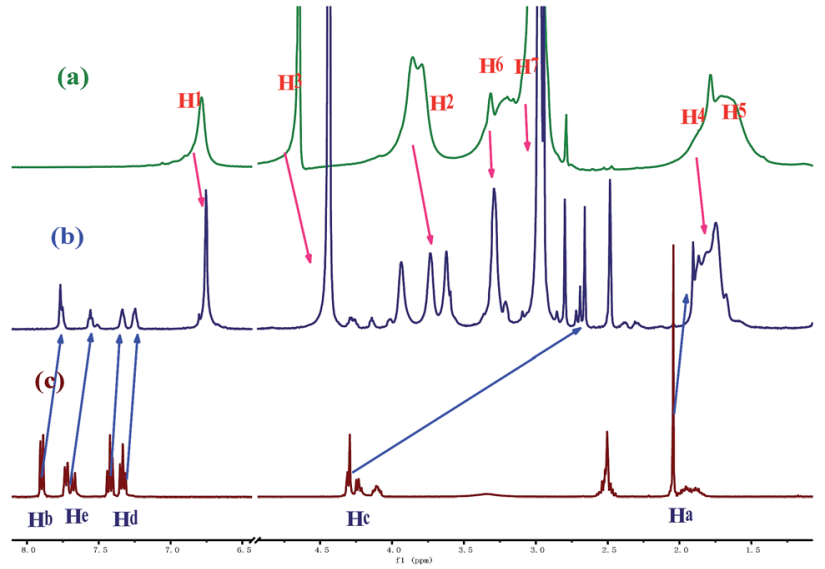

Fig. $5{ }^{1} \mathrm{H}$-NMR spectra $(600 \mathrm{MHz}, 298 \mathrm{~K})$ of (a) AWP5 $\left(1 \times 10^{-3} \mathrm{~mol}\right.$ $\mathrm{L}^{-1}$ in $\mathrm{H}_{2} \mathrm{O}$ ); (b) equimolar mixture of AWP5 and L-Met (1:1); and (c) LMet $\left(1 \times 10^{-3} \mathrm{~mol} \mathrm{~L}^{-1}\right.$ in DMSO- $\left.\mathrm{d}_{6}\right)$.

Furthermore, a 2D NOESY NMR study of a mixture of AWP5 $(10.0 \mathrm{mM})$ and $\mathrm{L}$-Met $(10.0 \mathrm{mM})$ in $\mathrm{D}_{2} \mathrm{O}$ was carried out to investigate the relative spatial positions of this host-guest

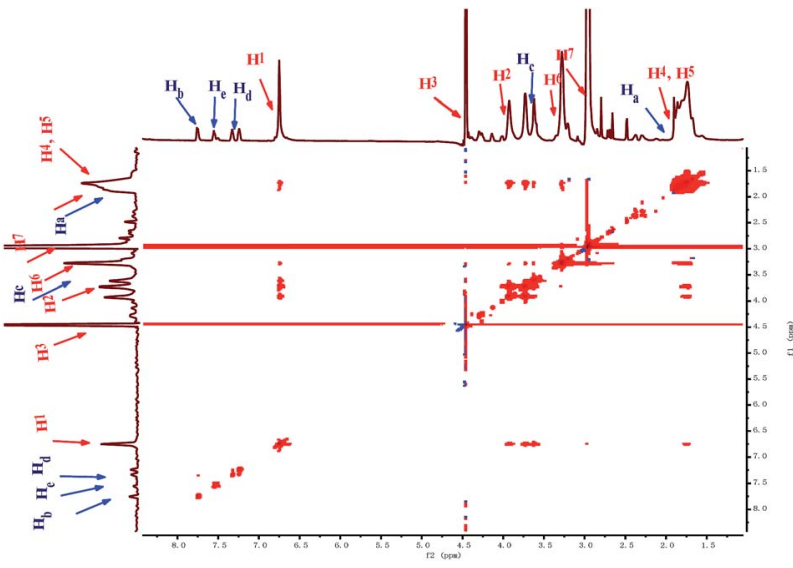

Fig. 6 NOESY-NMR spectra of $\left(600 \mathrm{MHz}, \mathrm{D}_{2} \mathrm{O}, 298 \mathrm{~K}\right)$ of AWP5 : LMet $=1: 1$.

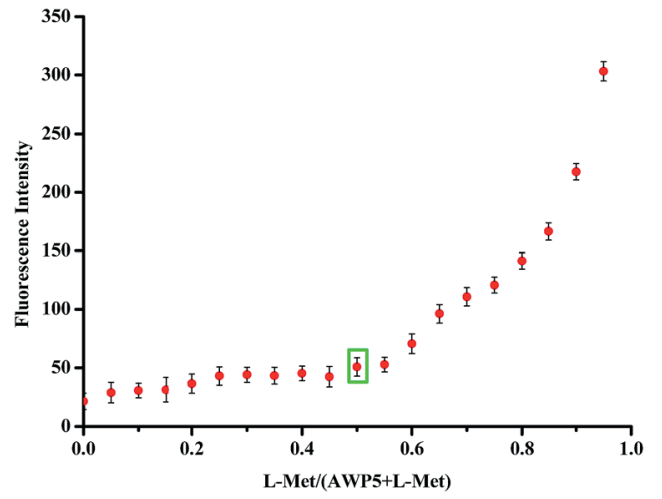

Fig. 7 Job plot for complexation between AWP5 and L-Met in $\mathrm{H}_{2} \mathrm{O}$.

complex. As shown in Fig. 6, clear correlation signals were observed between proton $\mathrm{H}^{1}$ of AWP5 and proton $\mathrm{H}^{\mathrm{a}}$ of L-Met, indicating that L-Met penetrated through the cavity of AWP5.

To confirm the binding stoichiometry between the sensor AWP5 and L-Met in $\mathrm{H}_{2} \mathrm{O}$, a job plot was constructed. The results illustrate that L-Met forms a 1 : 1 complex with AWP5 (Fig. 7). Furthermore, mass spectrometry experiments also support the abovementioned proposed host-guest mechanism. In the ESIMS of the sensor AWP5 and L-Met solution, (Fig. S13, ESI $\dagger$ ) a peak at $m / z=444.0376$ for [AWP5 $\left.+{ }_{\text {L-Met }}+4 \mathrm{Br}\right]^{5+}$ proved the $1: 1$ complexation stoichiometry between AWP5 and L-Met.

Through the abovementioned phenomena and description, a possible mechanism was proposed (Scheme 1). On addition of L-Met, AWP5 forms a stable inclusion complex with L-Met in solution because of their multiple interactions. The methylene groups of L-Met can result in $\mathrm{C}-\mathrm{H} \cdots \pi$ interactions with the pillar[5] arene group, whereas the amino groups of L-Met can form hydrogen bonds with oxygen atoms of the pillar[5]arene group. In addition, electrostatic interactions occur between ammonium groups of AWP5 and carboxylic acid group of L-Met. These multiple interactions stabilize the resulting inclusion complex between AWP5 and L-Met.

\section{Conclusions}

In summary, we employed cationic pillar[5]arene (AWP5) as a water-soluble chemosensor for the recognition of amino acids. The chemosensor AWP5 could fluorescently detect L-Met in water with high selectivity and sensitivity by a host-guest mechanism. Moreover, the detection limit of the sensor AWP5 for L-Met was $5.46 \times 10^{-7} \mathrm{~mol} \mathrm{~L}^{-1}$, which indicated that the sensor AWP5 could be useful as a highly selective and sensitive sensor for detecting L-Met. The chemosensor AWP5 can thus serve as a practical and convenient fluorescence test kit to detect L-Met.

\section{Acknowledgements}

This study was supported by the National Natural Science Foundation of China (NSFC) (No. 21662031; 21661028; 21574104; 21262032), the Natural Science Foundation of Gansu 
Province (1506RJZA273) and the Program for Changjiang Scholars and Innovative Research Team in University of Ministry of Education of China (IRT 15R56).

\section{Notes and references}

1 G. L. Cantoni, J. Am. Chem. Soc., 1952, 74, 2942.

2 H. Borsook and J. W. Dubnoff, J. Biol. Chem., 1947, 171, 363. 3 H. A. Friedel, K. L. Goa and P. Benfield, Drugs, 1989, 38, 389. 4 Y. k. Yue, F. Huo, P. Ning, Y. Zhang, J. Chao, X. Meng and C. Yin, J. Am. Chem. Soc., 2017, 139, 3181.

5 Y. Konya, M. Taniguchi and E. Fukusaki, J. Biosci. Bioeng., 2017, 123, 126.

6 E. Monteagudo, A. Virgili, T. Parella and P. T. Míriam, Anal. Chem., 2017, 89, 4939.

7 H. J. Issaq and K. C. Chan, Electrophoresis, 1995, 16, 467.

8 M. R. Silva, R. M. Olivas, O. F. X. Donard and M. Lamotte, Appl. Organomet. Chem., 1997, 11, 21.

9 T. Ogoshi, S. Kanai, S. Fujinami, T. Yamagishi and Y. J. Nakamoto, J. Am. Chem. Soc., 2008, 130, 5022.

10 D. Cao, Y. Kou, J. Liang, Z. Chen, L. Wang and H. Meier, Angew. Chem., Int. Ed., 2009, 48, 9721.

11 P. J. Cragg and K. Sharma, Chem. Soc. Rev., 2012, 41, 597.

12 M. Xue, Y. Yang, X. Chi, Z. Zhang and F. Huang, Acc. Chem. Res., 2012, 45, 1294.

13 G. Yu, D. Wu, Y. Li, Z. Zhang, L. Shao, J. Zhou, Q. Hu, G. Tang and F. Huang, Chem. Sci., 2016, 7, 3017.

14 S. Dasgupta, A. Chowdhurya and P. S. Mukherjee, RSC Adv., 2015, 5, 85791.

15 M. Bojtár, Z. Szakács, D. Hessz, M. Kubinyibc and I. Bitter, $R S C A d v ., 2015$, 5, 26504.

16 S. K. Wang, L. L. Tan, D. X. Chen, N. Song, G. Xi, S. X. A. Zhang, C. Li and Y. W. Yang, Org. Biomol. Chem., 2012, 10, 9405 .

17 K. Jie, Y. Zhou, Y. Yao, B. Shi and F. Huang, J. Am. Chem. Soc., 2015, 137, 10472.

18 T. Ogoshi, S. Takashima and T. Yamagishi, J. Am. Chem. Soc., 2015, 137, 10962.

19 B. Shi, K. Jie, Y. Zhou, J. Zhou, D. Xia and F. Huang, J. Am. Chem. Soc., 2016, 138, 80.

20 B. Shi, D. Xia and Y. Yao, Chem. Commun., 2014, 50, 13932.

21 L. L. Tan, H. Li, Y. Tao, S. X. A. Zhang, B. Wang and Y. W. Yang, Adv. Mater., 2014, 26, 7027.

22 T. Ogoshi, K. Yoshikoshi, R. Sueto, H. Nishihara and T. Yamagishi, Angew. Chem., Int. Ed., 2015, 54, 6566.

23 T. Ogoshi, R. Sueto, K. Yoshikoshi, Y. Sakata, S. Akine and T. Yamagishi, Angew. Chem., 2015, 127, 9987.

24 Y. Chang, C. Hou, J. Ren, X. Xin, Y. Pei, Y. Lu, S. Cao and Z. Pei, Chem. Commun., 2016, 52, 9578.

25 X. Wu, Y. Li, C. Lin, X. Y. Hu and L. Wang, Chem. Commun., 2015, 51, 6832 .
26 Y. Chang, K. Yang, P. Wei, S. Huang, Y. Pei, W. Zhao and Z. Pei, Angew. Chem., Int. Ed., 2014, 53, 13126.

27 Y. Cao, X. Y. Hu, Y. Li, X. Zou, S. Xiong, C. Lin, Y. Z. Shen and L. Wang, J. Am. Chem. Soc., 2014, 136, 10762.

28 Q. Duan, Y. Cao, Y. Li, X. Hu, T. Xiao, C. Lin, Y. Pan and L. Wang, J. Am. Chem. Soc., 2013, 135, 10542.

29 L. Gao, B. Zheng, W. Chen and C. ASchalley, Chem. Commun., 2015, 51, 14901.

30 Y. Wang, J. Du, Y. Wang, Q. Jin and J. Ji, Chem. Commun., 2015, 51, 2999.

31 T. Ogoshi, K. Kida and T. Yamagishi, J. Am. Chem. Soc., 2012, 134, 20146.

32 M. Xue, Y. Yang, X. Chi, X. Yan and F. Huang, Chem. Rev., 2015, 115, 7398.

33 W. Zheng, L. J. Chen, G. Yang, B. Sun, X. Wang, B. Jiang, G. Q. Yin, L. Zhang, X. Li, M. Liu, G. Chen and H. B. Yang, J. Am. Chem. Soc., 2016, 138, 4927.

34 B. Jiang, J. Zhang, J. Q. Ma, W. Zheng, L. J. Chen, B. Sun, C. Li, B. W. Hu, H. Tan, X. Li and H. B. Yang, J. Am. Chem. Soc., 2016, 138, 738.

35 L. L. Tan, H. Li, Y. C. Qiu, D. X. Chen, X. Wang, R. Y. Pan, Y. Wang, S. X. A. Zhang, B. Wang and Y. W. Yang, Chem. Sci., 2015, 6, 1640.

36 Y. Fang, X. Yuan, L. Wu, Z. Peng, W. Feng, N. Liu, D. Xu, S. Li, A. Sengupta, P. K. Mohapatra and L. Yuan, Chem. Commun., 2015, 51, 4263.

37 J. Bi, X. Zeng, D. Tian and H. Li, Org. Lett., 2016, 18, 1092.

38 Y. Ma, X. Ji, F. Xiang, X. Chi, C. Han, J. He, Z. Abliz, W. Chen and F. Huang, Chem. Commun., 2011, 47, 12340.

39 T. Ogoshi, M. Hashizume, T. Yamagishi and Y. Nakamoto, Chem. Commun., 2010, 46, 3708.

40 X. Y. Hu, X. Liu, W. Zhang, S. Qin, C. Yao, Y. Li, D. Cao, L. Peng and L. Wang, Chem. Mater., 2016, 28, 3778.

41 Q. Lin, T. T. Lu, X. Zhu, T. B. Wei, H. Li and Y. M. Zhang, Chem. Sci., 2016, 75, 341.

42 Q. Lin, T. T. Lu, J. C. Lou, G. Y. Wu, T. B. Wei and Y. M. Zhang, Chem. Commun., 2015, 51, 12224.

43 Q. Lin, T. T. Lu, X. Zhu, B. Sun, Q. P. Yang, T. B. Wei and Y. M. Zhang, Chem. Commun., 2015, 51, 1635.

44 Q. Lin, B. Sun, Q. P. Yang, Y. P. Fu, X. Zhu, T. B. Wei and Y. M. Zhang, Chem.-Eur. J., 2014, 20, 11457.

45 Q. Lin, X. Liu, T. B. Wei and Y. M. Zhang, Chem.-Asian J., 2013, 8, 3015.

46 T. B. Wei, J. F. Chen, X. B. Cheng, H. Li, Q. Lin, H. Yao and Y. M. Zhang, RSC Adv., 2016, 6, 65898.

47 G. Y. Wu, B. B. Shi, Q. Lin, H. Li, Y. M. Zhang, H. Yao and T. B. Wei, $R S C A d v ., 2015$, 5, 4958.

48 T. B. Wei, J. F. Chen, X. B. Cheng, H. Li, B. B. Han, Y. M. Zhang, H. Yao and Q. Lin, Org. Chem. Front., 2017, 4, 210.

49 Analytical Methods Committee, Analyst, 1987, 112, 199. 